fauna of Liverpool Bay published by the L.M.B.C., he declared the building open for work, and then the party entered and proceeded to examine the results of the forenoon's dredging, laid out in dishes and under microscopes. At two o'clock the Governor and the Bishop were entertained to luncheon at the Bellevue Hotel by the L.M.B.C., Prof. Herdman being in the chair, with the Governor on the right and the Bishop on the left. Mr. I. C. Thompson, Hon. Sec. L.M.B.C., occupied the other end of the table, and about seventy in all sat down to luncheon, including the President and Secretary and some other members of the Isle of Man Natural History Society. The Governor proposed the toast of "The Liverpool Marine Biology Committee," to which Prof. Herdman replied.

The whole of the following day was spent in dredging and tow-netting from the Mallard to the west and south of Port Erin at the following localities:-

(I) 3 miles west of Fleshwick: 20 fathoms, 6 hauls of dredge: good varied ground, old shells, \&c.

(2) I4 miles west of Dalby: 60 fathoms, 2 hauls; sticky clay mud, with few animals.

(3) 8 miles west of Fleshwick: 33 fathoms, 3 hauls.

(4) 6 miles west of Port Erin: 24 fathoms, 2 hauls.

(5) I mile west of Calf : 20 fathoms, 2 hauls.

(6) Off Kitterland, Calf Sound: I7 fathoms, I haul.

At each of these localities, besides the ordinary large dredge, tow-nets were used, and also Mr. Walker's small dredge with a canvas bag for bringing up samples of the bottom to be washed for small Crustacea, \&c.

On the following day (June 6), on the way back to Liverpool, dredging from the Mallard was conducted at the following places:-

(1) 20 miles south-east from Port St. Mary : 26 fathoms.

(2) 25 miles south-east from Port St. Mary : 23 fathoms.

Both of these localities were good productive ground, and large hauls were obtained.

(3) 20 miles north-west from the Bar: I 8 fathoms.

(4) 15 miles north-west from the Bar: 16 fathoms.

On all these occasions, besides the surface tow-nets, a bottom tow-net was attached a little way in front of the dredge, and appeared to work well; its contents were usually a good deal different from those of the surface nets.

Amongst the forms dredged in these two days were :Clathria seriata, Spongelia fragilis, Sarcodictyon catenata, Palmipes memoranaceus, Stichaster roseus, Porania pulvillus, Antedon rosaceus, Adamsia pailliata, Crania anomala, Pansora incquivalvis, Cynthia echinata, and the rare little Ascidian Forbesella tessellata, and a large number of other species, representing most of the invertebrate groups, which have not yet been sorted out and identified. A list of the species previously found in the neighbourhood of Port Erin will be found in "Fauna of Liverpool Bay," vol. i. pp. 318-4I.

The Liverpool Marine Biology Committee's Station at Port Erin is now open, and is provided with a few microscopes, microtome, ordinary reagents, dishes, \&c. Any biolingists wishing to go there for collecting or other work are requested to apply for particulars to Prof. Herdman, or to Mr. I. C. Thompson, 4 Lord Street, Liverpool.

\section{THE ANNUAL VISITATION OF THE} GREENWICH OBSERVATORY.

THE report of the Astronomer-Royal to the Board of Visitors this year commences with a reference to the loss sustained by the Observatory by the death of Sir G. B. Airy, who for sixty years was closely connected with the working of this institution.

As regards the buildings, that of the south wing of the proposed Physical Observatory has been authorized by No. I I 8 I, VOL. 46$]$ the Admiralty, considerably more space being required for the storing of chronometers and deck watches. The buildings of the three other wings and the two upper stories of the central tower have, for the present, been laid aside, sufficient provision not being made for them in the present financial year. The new 36 -foot dome, which is being provided for the efficient working of the 28 -inch refractor, is still in course of erection, while the pair of semi-domes for the Transit Pavilion in the Front Court has been found to be quite satisfactory. The electric light installation, which has in a former report been suggested by the Astronomer-Royal for the photographic equatorial and for other instruments, has been sanctioned by the Admiralty, and will, during the course of the present year, be provided. The advantages of such a means of lighting will at once make themselves apparent, for by the old method the storage cells had to be charged from primary batteries.

The Observatory, by the will of the late Sir George Airy, has had several valuable works bequeathed to it. Mr. Wilfred Airy has as yet transferred 94 volumes and I34 unbound tracts, which will form a valuable addition to the library, together with the manuscript containing the calculations of Sir George Airy's numerical lunar theory. His bust, by Foley, has also been received and is now placed in the Octagon Room.

With regard to the work done with the transit-circle, the number of observations was not so great as in former years, as the object-glass was removed for repolishing on August 10 to October 5. The definition and colourcorrection of this glass has been greatly improved by $\mathrm{Mr}$. Simms. New steel screws to the R.A. and Z.D. micrometers were added at the same time, and the wire system also received a slight modification. The wires are ten in number, distant from each other by exact multiples of a screw-revolution, and so arranged that the mean of the ten nearly coincides with one of them. A little computation is thus saved in taking the mean of a transit, and the only thing lost is symmetry in the arrangement.

During the rest of the year the sun, moon, and planets have been regularly observed on the meridian as before :-

Transits, the separate limbs being counted as

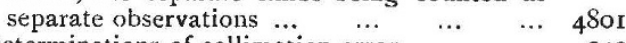

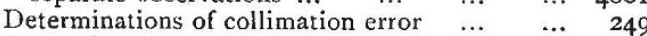

Determinations of level error $\quad \ldots \quad \ldots \quad \ldots \quad \ldots \quad 335$

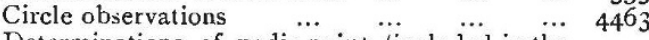

Determinations of nadir point (included in the number of circle observations)

Reflexion observations of stars (similarly included) ...

The annual catalogue of stars observed in I89I contains 18 I 3 stars.

The results from the observations for the determination of variation of personal equation with stellar magnitude, indicated that there was a general tendency with all the observers to observe stars later when the light was diminished by placing a gauze screen before the objectglass; but it was stated that "it is not clear that we are here measuring a real change of personal equation in observations of fainter stars, as the introduction of the screen modifies the image of the star, and this modification of the image may give rise to a change of personal equation unconnected with the diminution of brightness."

It is noted that as the external thermometer rises there is a nearly uniform decrease of the readings of the internal thermometers over that of the standard exterior thermometer, the excess vanishing at something over $70^{\circ}$. This is accounted for by the variation of the temperature of the walis of the room, the permanent temperature of which is always slowly changing. 
The total number of observations made with the altazimuth in the year ending 1892 May 10 is as follows :Azimuths of the moon and stars

Azimuths of Mark I.

Azimuths of Mark II.

Zenith distances of the moon

Zenith distances of Mark I.

Zenith distances of Mark II.

$$
\begin{array}{lll}
\ldots & \ldots & 345 \\
\ldots & \ldots & 162 \\
\ldots & \ldots & 182 \\
\ldots & \ldots & 166 \\
\ldots & \cdots & 164
\end{array}
$$

These numbers are slightly greater than in recent years, owing to the fact that during August and September, when the transit-circle was under repair, the observations of the moon with the altazimuth were made throughout the lunation instead of being confined to the first and last quarters.

With regard to clocks and chronographs, we may mention that the daily rate of the sidereal standard clock underwent a very considerable disturbance, changing from a daily gain of $\mathrm{I}^{\circ} \mathrm{Os}$. to that of $2^{\circ} \mathrm{Os}$. The cause of this difference was due to some workmen who were fixing a new shelf, the necessary hammering setting up vibrations in the building.

With the reflex zenith tube, eighteen double observations of ' $\gamma$ Draconis have been made, but owing to the pressure of work the reductions are not yet complete.

Ten occultations of stars by the uneclipsed moon ( 8 disappearances and 2 reappearances) and 48 phenomena of Jupiter's satellites have been observed with the equatorials, or with the altazimuth. These observations are completely reduced to I89I December 3I. On the occasion of the partial eclipse of the moon on I 892 May I I, 7 disappearances and 3 reappearances were observed of the faint stars in a list prepared by $\mathrm{Mr}$. Crommelin ; and the times of transit of the shadow over some principal craters were also noted. But it is to be regretted that, although favoured by fine weather on this occasion, the Observatory was seriously crippled in their instrumental equipment, the 13 -inch refractor of the south-east equatorial and the Lassell 2 -feet reflector being both dismounted.

With the photographic equatorial, 301 plates with a total of II9O exposures have been taken on II 2 nights, many of these being taken for special investigations. Of these, 62 plates were taken to determine the relations between diameter of image, length of exposure, and brightness of the star, the results of which have already appeared in the Monthly Notices for January of this year. The discussion indicated that, through a range of exposures corresponding to 8 magnitudes, "the square root of the diameter increases as the logarithm of the exposure ; and further, that for equal photographic effects duration of exposure should vary inversely as the brightness of the star." These results were based on as many as 2200 measures of $\mathrm{I} 50$ starimages. The ríseaux seem to have given much trouble, the silver film developing pin-holes, the images of which resemble on the photographic plates those of stars. M. Gautier is now supplying the Observatory with two more, coated this time with a film of collodion, in the hopes that it may be freed from the deficiencies mentioned above. The catalogue which has been undertaken at Greenwich of the guiding stars for the zones $+60^{\circ}$ to the pole, $+25^{\circ}$ to $+29^{\circ}$, and $-3^{\circ}$ to $-5^{\circ}$, is very near completion. The catalogues of places (epoch 1900) are complete for the Greenwich zones $+65^{\circ}$ to $+80^{\circ}$ (the reductions for the circumpolar region being deferred), also for the zones $+60^{\circ}$ to $+64^{\circ}$ to be photographed at Rome, and for the Oxford zones $+25^{\circ}$ to $+29^{\circ}$. The stars for the San Fernando zone $\left(-3^{\circ}\right.$ to $\left.-5^{\circ}\right)$ have all been selected, and their places have been computed for those between R.A. I hh. and I $8 \mathrm{~h}$.

Spectroscopic and Photographic Observations.-The observations of the displacement of the lines in stellar spectra for the determination of their motion in the line of sight have not this year been regularly continued; a preliminary discussion of the former observations suggesting that they were affected to some extent by the No. I I 8 I, VOL. 46] position of the spectroscope, Vega and Altair were ob served during the summer and autumn at as wide a range of hour-angle as possible, and with the spectroscope set to each of the four positions $0^{\circ}, 90^{\circ}, 180^{\circ}$, and $270^{\circ}$; the slit being parallel to the declination circle at $0^{\circ}$. The numbers of observations obtained of the $F$ line in the spectrum of Vega are: at $0^{\circ}, 39$; at $90^{\circ}, 42$; at $180^{\circ}, 36$; and at $270^{\circ}, 39$; and of the $F$ line in the spectrum of Altair: at $0^{\circ}, 30$; at $90^{\circ}, 32$; at $180^{\circ}, 26$; and at $270^{\circ}, 29$. The measures are now under discussion, and give clear indications of the existence of the systematic error referred to. The observations were interrupted by the dismounting of the $12 \frac{3}{4}$-inch telescope on 1891 November 19.

At the appearance of the new star in Auriga the southeast equatorial was unfortunately dismounted, but the object-glass presented to the Observatory by Sir Henry Thompson was mounted as quickly as possible on the Thompson telescope ; but alterations of the telescope tube were found necessary to bring the spectrum to focus on the photographic plate, and before these could be completed, the Nova had become nearly too faint for observation.

For the year I89I, 360 out of 365 photographs of the sun's surface have been selected for measurement ; 136 of these were sent to the Solar Pbysics Committee from India and Mauritius.

The solar activity has increased in a remarkable manner during the past year. While there were 175 days without spots in the year I 890 , there were only 2 I such days in I89I, and since $189 \mathrm{I}$ March 28 , the sun has not been free from spots on a single day on which it has been observed. The number of groups visible on the disk at the same time, and their average size and complexity, have all greatly increased during the past twelve months, the group of February 5-1 8 being the largest ever photographed at Greenwich. This group has had an unusually long life, appearing first on $189 \mathrm{r}$ November $\mathrm{I}_{5}$, and persisting till 1892 March 17.

Magnetic Observations. - The continuous register by photography of the magnetic elements has been satisfactorily maintained. It has been found that serious disturbances of the earth-current registers is due to the trains of the City and South London Electric Railway, situated at a distance of $2 \frac{1}{2}$ miles from the nearest earth plate, and about $4^{\frac{1}{2}}$ miles from the Observatory. The change of potential takes place every two or three minutes, varying in amount from "a small fraction of a volt to one-third of a volt or more."

The following are the principal results for the magnetic elements for 1891 :-

Mean declination (approximate) $\ldots . . . . .17^{\circ} 23^{\prime}$ W
Mean horizontal force $\ldots$

I.8253 (in Metric units).

Mean dip .. $67^{\circ} 19^{\prime} 49^{\prime \prime}$ (by 9 -inch needles) $67^{\circ} 2 \mathrm{I}^{\prime} \mathrm{O}^{\prime \prime}$ (by 6-inch needles) $67^{\circ} 23^{\prime} 22^{\prime \prime}$ (by 3 -inch needles).

In the year I 89 I there were five days of great magnetic disturbance, but there were also about twenty other days of lesser disturbance, for which tracings of the photographic curves will be published; these days having been selected in concert with M. Mascart according to the arrangement mentioned in the last report. The calculation of diurnal inequalities from five typical quiet days in each month, commenced in I 889 at Prof. Rücker's suggestion, has been continued.

From February 13 to 14 a very large disturbance was recorded, commencing a day after the large sun-spot was on the central meridian. Considerable magnetic disturbances also occurred on March 6, II, and 12. Other disturbances occurred on 1891 September 9, 1892 April 25-26 and May I, and may perhaps "be connected with spots then on the sun's disk."

Meteorological Observations.-The mean temperature of the year I89I was $48^{\circ} .4$, being $I^{\circ} \cdot I$ below the average 
of the fifty years, I84I-I 890 . The highest air temperature in the shade was $85^{\circ} \mathrm{I}$ on July 17 , and the lowest $12^{\circ} .0$ on January I0. The mean monthly temperature in I89I was below the average in all months excepting June, September, October, December. In January it was below the average by $4^{\circ} 4$, in April and August by $3^{\circ} \circ$, and in May by $2^{\circ} \cdot 8$.

The mean daily motion of the air in I89I was 278 miles, being 4 miles below the average of the preceding twenty-four years. The greatest daily motion was 960 miles on December Io, and the least 34 miles on February 23 and 24 . The greatest pressure registered was $3 \mathrm{I}^{\circ} 5$ lbs. on the square foot on November II. On December Io the pressure plate was not in action.

The number of hours of bright sunshine recorded during $189 \mathrm{I}$ by the Campbell-Stokes sunshine instrument was 1222, which is about 66 hours below the average of the preceding fourteen years, after making allowance for difference of the indications with the Campbell and Campbell-Stokes instruments respectively. The aggregate number of hours during which the sun was above the horizon was 4454 , so that the mean proportion of sunshine for the year was $0^{*} 274$, constant sunshine being represented by $\mathrm{I}$.

The rainfall in 1891 was $25^{\circ}$ inches, being $0^{\circ} 5$ inches above the average of the preceding fifty years.

Chronometers, Time Signals, and Longitude Operations.-The number of chronometers and deck watches now being tested at the Observatory is 157 (9I box chronometers, 19 pocket chronometers, and 47 deck watches). The annual competitive trial of chronometers commences on July 2 , and the trial of deck watches on October 22.

In the year ending $189 \mathrm{I}$ May IO, the average daily number of chronometers and deck watches being regularly rated was 243 , the total number received was 765 , the total issued 750 , and the number set to repair 442 .

At the annual trial of chronometers the performance was good, the average trial number of the first six was $2 \mathrm{I}^{\circ}$, which compares favourably with those of previous years.

The dropping of the time-balls is next referred to. The Greenwich ore was not raised on October I4, December Io and I3, I891, owing to the violence of the wind; on April I, I 892 , the springs of the mean solar clock failed to act, and on October 19 and November 22 failure in the connections was the cause.

The return signal from Deal was interrupted last November several times, owing to an accumulation of grease which had been applied to the piston. Signals from Devonport clock failed on $5 \mathrm{I}$ days, and those from the Westminster clock on 14 day's.

The publication of the observations for the ParisGreenwich longitude in 1888 , and of those for the Dunkerque-Greenwich longitude in 1889 , has been delayed pending a redetermination of the former longitude which was commenced on June 6 of the present year; and it is hoped to settle several questions of importance raised by the discussion of the results obtained in 1888 .

The first stage of the operations for the longitudes Montreal-Canso-Waterville-Greenwich was completed on May 23. The time of transmission along the cable Waterville-Canso was about a quarter of a second-a result confirmed by a rough comparison of signals on 1892 May II. Prof. McLeod, of Montreal, paid a similar preliminary visit to Canso in $189 \mathrm{I}$ June, and found an accordant value for the time of transmission. Four portable transits were used for the time determinations. These latter were made in all on 14 nights at Greenwich, I 2 at Waterville, and about the same number at Canso and Montreal. The preliminary reduction gives every promise of satisfactory accuracy at Greenwich and Waterville.

Captain Grant, R.E., has been at work at the ObservaNO. I I 8 I, vOL. 46$]$ tory practising the requisite transit observations for determining the boundary of Mashonaland.

In the Astronomer-Royal's general remarks at the conclusion of his report, he refers to a plan he has devised for making observations out of the meridian with a transitcircle. He proposes to have it so constructed that by means of a turn-table it can be placed and firmly fixed in certain definite azimuthal, the instrument "being used essentially as a transit-circle for a complete series of observations in the selected azimuths plane." This instrument, as he says, would advantageously replace the existing altazimuth, and could be used "not only for the important object of making extra-meridian observations of the moon but also for observations of the sun, planets, and stars (in the meridian as well as out of the meridian), for the elimination, as far as practicable, of systematic errors, and for the more accurate determination of astronomical constants." The aperture of the instrument he suggests should be 8 inches, with circles of 3 feet diameter, read by four microscopes, and he thinks that a suitable position for it could be found about 90 feet north of the declination magnet, where "an unobstructed view could be secured by mounting it with its axis at a height of about 20 feet above the ground."

\section{NOTES}

The Ladies' Soirée of the Royal Society is being held this evening as NATURE goes to press.

THE annual meeting of the American Association for the Advancement of Science will be held at Rochester, N.Y., from August 18 to 24 .

THE late Dr. W. J. Walker placed at the disposal of the Boston Society of Natural History a grand honorary prize "for such investigation or discovery as may seem to deserve it, provided such investigation or discovery shall have been made known or published in the United States at least one year previous to the time of award." This prize has been unanimously awarded to Prof. James D. Dana. In recognition of the value of Prof. Dana's scientific work, and in testimony of the Society's high appreciation of his services to science, the maximum sum of one thousand dollars has been awarded.

In the new number of the Journal of the Marine Biological Association Mr. Ernest W. L. Holt gives an interesting account of the work he has lately done in connection with his North Sea investigations. The objects of these investigations, as explained in the report of Mr. Calderwood, the Director of the Plymouth Laboratory, are:-(I) to prepare a history of the North Sea trawling grounds, comparing the present condition with the condition say twenty or thirty years ago, when comparatively few boats were at work; (2) to continue, verify, and extend operations as to the average sizes at which the various food-fishes become sexually mature; (3) to collect statistics as to the sizes of all the fish captured in the vicinity of the Dogger Banks and the region lying to the eastward, so that the number of immature fish annually captured may be esti, mated; (4) to make experiments with beam trawl nets of various meshes, with a view to determine the relation, if any, between size of mesh and size of fish taken. It is obvious that a considerable time must elapse before trustworthy data can be collected on all these points by one inquirer. Mr. Calderwood therefore notes that in Mr. Holt's early reports it has been thought advisable not to treat each heading in detail, since one season of the year may be more suitable for collecting information on one point than on another, but rather simply to state the results of work accomplished. During the spawning season most attention must necessarily be given to heading No. 2, so that in Mr. Holt's present report the relation of size to immaturity is principally mentioned. Work of a similar nature done by Mr. Holt himself in Ireland, by Dr. Fulton in Scotland, 